\title{
Hydrogen production via methane pyrolysis in a liquid metal bubble column reactor with a packed bed
}

\author{
T. Geißler ${ }^{1}$, A. Abánades ${ }^{2,3}$, A. Heinzel ${ }^{1}$, K. Mehravaran $^{2}$, G. Müller ${ }^{1}$, R. K. Rathnam ${ }^{2}$, C. \\ Rubbia $^{2,4}$, D. Salmieri ${ }^{2,4}$, L. Stoppel ${ }^{1}$, S. Stückrad ${ }^{2}$, A. Weisenburger ${ }^{1}$, H. Wenninger ${ }^{4}$, Th. \\ Wetzel $^{1}$

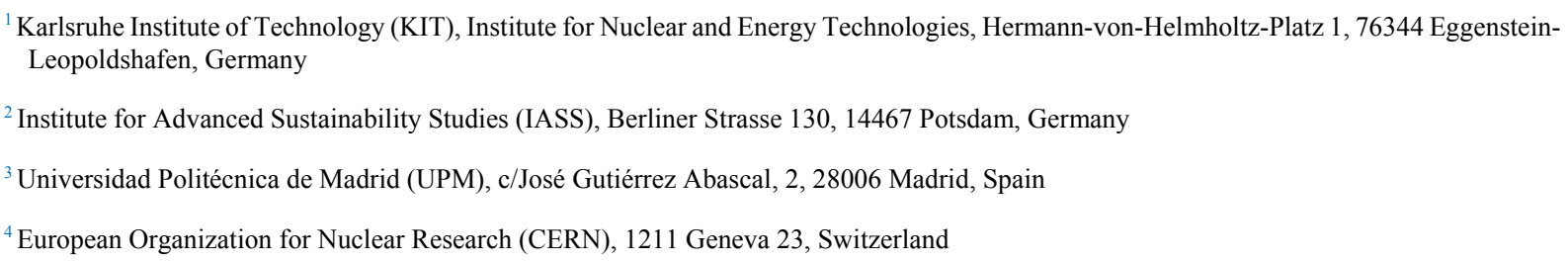

Keywords: packed bed, liquid metal, bubble column reactor, methane cracking, hydrogen production

\section{Abstract}

Methane pyrolysis experiments using a quartz glass-steel bubble column reactor filled with liquid tin and cylindrical quartz glass rings serving as a packed bed were conducted at various liquid metal temperature levels in the range of $930{ }^{\circ} \mathrm{C}$ to $1175^{\circ} \mathrm{C}$. Besides the liquid metal temperature, special attention was paid to the influence of the feed gas volume flow rate in the range of 50-200 $\mathrm{ml} / \mathrm{min}$ and the inlet feed gas dilution with nitrogen. Increasing liquid metal temperatures resulted in increasing hydrogen yields, leading to a maximum hydrogen yield of $78 \%$ at $1175{ }^{\circ} \mathrm{C}$ and $50 \mathrm{ml} / \mathrm{min}$ methane volume flow rate. Within all experimental runs, less than 1.5 mol- $\%$ intermediate products were detected in the product gas. The produced carbon appeared as a powder consisting of flake shaped agglomerations in the size range of $15 \mu \mathrm{m}$ to $20 \mu \mathrm{m}$, wherein the particle size varied from $40 \mathrm{~nm}$ to $100 \mathrm{~nm}$. During the experiments, the produced carbon was completely separated and accumulated at the top surface of the liquid metal. Only minor quantities were transported with the off gas stream. Within the liquid metal inventory, a thin carbon layer of about $10 \mu \mathrm{m}$, probably partly showing the formation of nanotubes, in the hot reaction zone, had been deposited on the quartz glass reactor wall.

\section{Introduction}

A low-carbon energy system and economy is the ultimate goal of developing renewable energy technologies. Nevertheless, the transition to such a low-carbon economy will require not only the development of innovative solutions but also a continued utilization of fossil fuels for decades to come. We are hereby developing an alternative solution-specifically applicable to the energy generation with natural gas $(\mathrm{NG})$ - in which NG is transformed into hydrogen 
without any $\mathrm{CO}_{2}$ emissions. The studied endothermic process with a standard reaction enthalpy of $74.85 \mathrm{~kJ} / \mathrm{mol}$ is the well-known pyrolysis of methane (representing natural gas in a first approximation), also called thermal methane cracking or simply methane decomposition.

$$
\mathrm{CH}_{4}(\mathrm{G}) \rightarrow \mathrm{C}(\mathrm{S})+2 \mathrm{H}_{2}(\mathrm{G}) \quad \Delta \mathrm{H}_{R}^{0}=74.85 \frac{\mathrm{kJ}}{\mathrm{mol}}
$$

The $\mathrm{H}_{2}$ from the reaction will be in gaseous form under all considered conditions, while the $\mathrm{C}$ is produced in solid form, which will permanently eliminate direct $\mathrm{CO}_{2}$ by using the solid carbon as raw material for further purposes such as color pigments or tires. Potential intermediate products known to be formed during the decomposition process are ethane, ethylene and acetylene, considering the proposed step-wise dehydrogenation mechanism [1], whereas Polycyclic Aromatic Hydrocarbons (PAH) might form as by-products.

The main drawback of former attempts to realize this decomposition process - mainly in tubular reactors - is the deposition of solid carbon layers on the heated reactor walls, subsequently leading to complete reactor blockage [2]. Removing these carbon layers has been a severe problem, which has so far prevented continuous large scale industrial application of this process. An alternative approach for the continuous decomposition of hydrocarbons is the utilization of liquid metals as a heat transfer fluid in a bubble column reactor. The liquid metal is chemically stable and applicable at temperatures above $1200{ }^{\circ} \mathrm{C}$. In the investigated process, methane gas is injected into a liquid metal bubble column and decomposes inside of the formed bubbles which are rising up in the reactor. The bubble opens at the upper interface of the liquid metal, releasing the produced carbon and hydrogen but also the remaining methane gas and the formed gaseous intermediates. The energy efficiency for such a methane pyrolysis process in a liquid metal bubble column reactor cannot be reliably established, based on existing laboratory scale experiments as the design for a large scale facility is not yet clear. In general, depending on the feed gas stream, energy is necessary for the endothermic reaction as well as for heating the methane gas and to maintain the liquid tin at reaction temperature, while the hot product gases and the produced carbon leave the reactor. Additionally, the application of carbon and product gas separation technologies consume an unknown amount of energy, whereas heat recuperation could counteract. Also the energy needed to cover the heat loss of the liquid bubble column strongly depends on the insulation and finally on the future reactor design. In general and in comparison with other hydrogen production technologies, such as steam reforming (74 $\%$ ) and coal gasification (60\%), the energy efficiency in transformation for methane pyrolysis processes is about $55 \%$, whereas the application of potential carbon capture and storage (CCS) technologies reduces the energy efficiency to $54 \%$ for the steam reforming process, 
respectively $43 \%$ for coal gasification [3]. In this scenario, hydrogen production by methane pyrolysis could become competitive.

After a patent from Tyrer et al. [4] in 1931, one of the first authors who proposed the decomposition of natural gas for hydrogen production by applying liquid tin as heat transfer fluid was Steinberg [5]. Martynov et al. [6] and Gulevich et al. [7] proposed a hydrogen production process by using heavy liquid metal coolants $(\mathrm{Pb}-\mathrm{Bi})$ while the methane for the pyrolysis reaction is fed to the lower section of a reaction vessel. Paxman et al. [8] published theoretical investigations of methane cracking in a bubble column reactor with different injector designs ( $6 \mathrm{~mm}$ and $3 \mathrm{~mm}$ tube, $7 \mu \mathrm{m}$ and $0.5 \mu \mathrm{m}$ porous sparger). In their most recent study they presented preliminary experimental runs in a blank tubular reactor without applying liquid metal. The concept published by Schultz et al. [9] for hydrogen production in liquid metals is based on the utilization of a capillary reactor. In their first experiment at $1100{ }^{\circ} \mathrm{C}$, they achieved an average methane conversion of $32 \%$. After $5 \mathrm{~h}$ of operation, no carbon deposition on the hot wall of the capillary reactor was found. So far, methane pyrolysis experiments in liquid metal bubble column reactors were conducted by Serban et al. [10], Schultz et al. [9], Plevan et al. [11] and Geißler et al. [12]. Serban et al. [10] operated a heated stainless steel vertical microreactor, $355.6 \mathrm{~mm}$ long with a diameter of $25.4 \mathrm{~mm}$ and placed a stainless steel cup of diameter $12.7 \mathrm{~mm}$ inside. The cup was either filled with tin or lead or a tin/packed bed combination at a filling level of $101.6 \mathrm{~mm}$. Natural gas was injected from the top inside of the reactor either by a $5.33 \mathrm{~mm}$ or a $0.51 \mathrm{~mm}$ stainless feed tube or a porous metal sparger. With this setup, they achieved a maximum methane conversion of $57 \%$ at $750{ }^{\circ} \mathrm{C}$ and volume flow rates around $10 \mathrm{ml} / \mathrm{min}$ using tin and $\mathrm{SiC}$ as a packed bed while injecting the gas via a porous metal sparger. Plevan et al. [11] conducted experiments in a stainless steel reactor, $1150 \mathrm{~mm}$ heating length with a diameter of $35.9 \mathrm{~mm}$ and a pure tin filling level of $600 \mathrm{~mm}$, injecting the methane gas from the bottom using a $1 \mathrm{~mm}$ single orifice and applying volume flow rates in the range of 5-200 $\mathrm{mln} / \mathrm{min}$. With this setup, they reported a maximum methane conversion of 18 $\%$ at $900{ }^{\circ} \mathrm{C}$. Most recent experiments in a liquid metal bubble column reactor were presented by Geißler et al. [12]. They conducted experiments in a quartz glass reactor, filled with quartz glass fragments and tin, $1150 \mathrm{~mm}$ heating length and $1100 \mathrm{~mm}$ filling level, injecting the methane gas from the bottom using a $0.5 \mathrm{~mm}$ single orifice. Within the investigated temperature levels between $820{ }^{\circ} \mathrm{C}$ and $1000{ }^{\circ} \mathrm{C}$ and a volume flow rates between $50-200 \mathrm{ml} / \mathrm{min}$, they reached a maximum hydrogen yield of around $30 \%$.

With regards to the reactor design, both in Serban et al. [10] and Plevan et al. [11] the main part of the reaction most likely could have taken place in the heated tubular part above the liquid 
metal interface, which implied $71 \%$ of the total heated reactor volume in the work from Serban et al. [10] respectively $48 \%$ in the reactor system from Plevan et al. [11]. In Geißler et al. [12], due to the enhanced filling level, the heated tubular part of the reactor implied only $4 \%$ of the overall heating length. Although in Geißler et al. [12] the heated upper part is smaller compared to the other authors, reaction in this area will always influence the methane conversion. When operating a liquid metal bubble column, reaction next to the liquid metal phase can never be avoided, as the liquid metal transfer heat into the upper part due to radiation, conduction and at least by releasing the hot gas bubbles. A comparison of the mean residence time calculations, both in the liquid metal phase and in the upper tubular part, are shown in Table 1, whereas the volume flow rate was adapted to the predominant temperature for each author, assuming a constant ambient pressure of 1.0135 bar above the liquid metal interface. For estimating the gas residence time in the liquid metal part, the correlation from Andreini et al. [13] with potential bubble diameter from $4 \mathrm{~mm}$ to $16 \mathrm{~mm}$ were used. This correlation was used as a first approximation, which nevertheless probably underestimates the gas residence time applying a packed bed up to $1000{ }^{\circ} \mathrm{C}$, as Andreini et al. [13] conducted experiments in pure tin at $262{ }^{\circ} \mathrm{C}$.

Table 1: Comparison of potential residence times in the liquid phase $\tau_{\mathrm{LM}}$ using the correlation from Andreini et al. [13] for the terminal bubble velocity in tin $(\mathrm{dB}=4-16 \mathrm{~mm})$ and the mean residence time in the heated tubular part $\tau_{\mathrm{UP}}$ at different operating conditions depending on the experiments of the listed authors.

\begin{tabular}{llcc}
\hline Author & Operating conditions & $\boldsymbol{\tau}_{\mathbf{L M}}(\mathbf{s})$ & $\boldsymbol{\tau}_{\mathbf{U P}}$ (s) \\
\hline Serban et al. [10] & $10 \mathrm{ml} / \mathrm{min}, 750{ }^{\circ} \mathrm{C}$ & $0.5-0.3$ & 51.5 \\
Plevan et al. [11] & $5 \mathrm{ml} / \mathrm{min}, 900{ }^{\circ} \mathrm{C}$ & $2.7-1.7$ & 1555.7 \\
Geißler et al. [12] & $50 \mathrm{ml} / \mathrm{min}, 1000{ }^{\circ} \mathrm{C}$ & $4.9-3.2$ & 16.7 \\
\hline Serban et al. [10] & $50 \mathrm{ml} / \mathrm{min}, 1000{ }^{\circ} \mathrm{C}$ & $0.5-0.3$ & 8.3 \\
Plevan et al. [11] & $50 \mathrm{ml} / \mathrm{min}, 1000{ }^{\circ} \mathrm{C}$ & $2.7-1.7$ & 143.3 \\
\hline
\end{tabular}

To compare the gas to liquid residence time ratios of the different authors, the reference operating condition was set to $50 \mathrm{ml} / \mathrm{min}$ gas volume flow rate and $1000{ }^{\circ} \mathrm{C}$ reactor temperature, also listed in Table 1. Although enhanced methane conversion in the reactor system is intended, it is significantly important in which region the conversion takes place. As the heated upper part is comparable with a tubular reactor and therefore has the drawbacks due to solid carbon deposition on the hot reactor wall [2], a continuous operation of the process could be endangered. In general, strong volume flow rate dependency on the methane conversion can be interpreted with predominant reaction in the upper part, as the gas residence 
time in a tube is strongly dependent on the volume flow rate, keeping pressure and temperature constant. Whereas in the liquid phase, according to the correlation of Andreini et al. [13], the bubble rise velocity varies between $222 \mathrm{~mm} / \mathrm{s}$ and $344 \mathrm{~mm} / \mathrm{s}$ for a wide range of bubble diameters between $4 \mathrm{~mm}$ and $16 \mathrm{~mm}$. Therefore even for significant changes in bubble diameters, the residence time in the liquid phase has minor influence on the resulting methane conversion or the hydrogen yield.

Within this study, we present our most recent experimental results on hydrogen production in a liquid metal bubble column reactor. In contrast to mainly Geißler et al. [11], the current study includes three major changes to the liquid metal-packed bed reactor design: a higher maximum operating temperature, a different packed bed geometry and results on the influence of feed gas dilution. The enhanced maximum operating temperature of $1175^{\circ} \mathrm{C}$ has not been realized in a liquid metal reactor for methane pyrolysis until now. However, based on the information available from previous studies, it is clear that temperatures higher than $1000{ }^{\circ} \mathrm{C}$ are required to attain significant levels of hydrogen yield/methane conversion. This paper describes the experimental investigations with the updated reactor and discusses the results attained thereof.

\section{Experimental Setup}

Experimental investigations on hydrogen production by methane cracking in a liquid metal were performed at the liquid metal laboratory (KALLA) of the Karlsruhe Institute of Technology (KIT). Because of its broad liquid range $\left(232-2600{ }^{\circ} \mathrm{C}\right)$ that encompasses the intended methane cracking reaction temperatures $\left(930-1175^{\circ} \mathrm{C}\right)$ proposed for this study and its extremely low vapour pressure of 3.21E-07 bar at $1000^{\circ} \mathrm{C}[14]$, tin has been chosen as the heat transfer fluid for the reactor. One of the key issues when designing a liquid metal bubble column reactor - already at lab scale - is the strong corrosion of most high temperature structural materials in liquid tin at high temperatures. This requires the development of a reactor made of a combination of quartz glass and stainless steel, as shown in Fig. 1. In this setup, a quartz glass tube with a diameter of $40.6 \mathrm{~mm}$ and a length of $1268 \mathrm{~mm}$ was supported by a high temperature stainless steel tube with a diameter of $49.25 \mathrm{~mm}$ and a length of $1150 \mathrm{~mm}$. Both, the stainless steel tube and the inner quartz glass tube were placed inside of an electrically heated furnace with three temperature zones and a maximum operating temperature of $1200^{\circ} \mathrm{C}$. The upper part of the quartz glass tube protruded over the furnace and was insulated separately. The temperature inside of the liquid metal reactor was monitored by type $\mathrm{K}$ thermocouples at 9 vertical positions along the reactor, all placed in an alumina tube. 

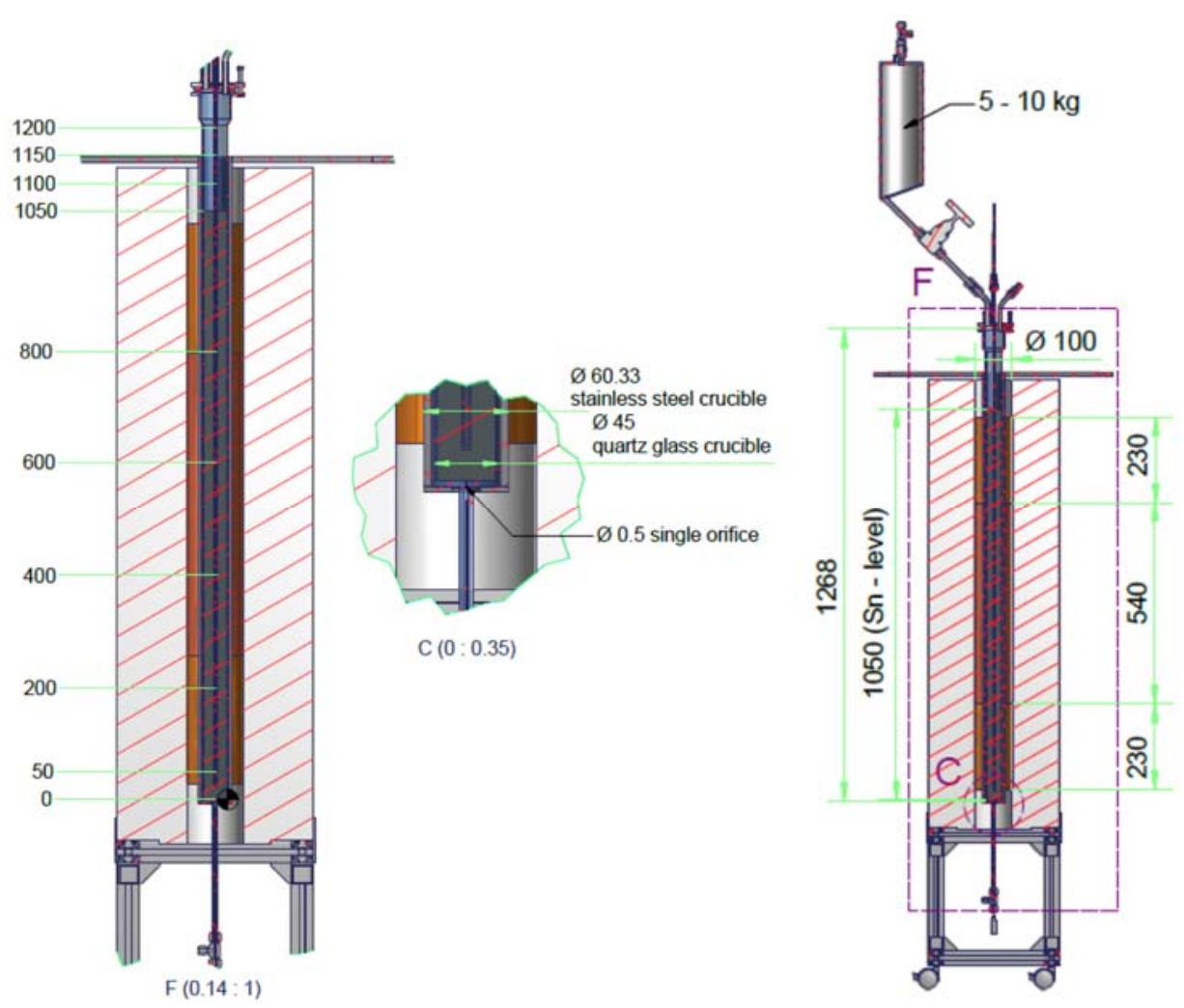

Fig. 1: Experimental reactor design.

The measured temperature at a level of $600 \mathrm{~mm}$, in the middle of the reaction zone, was used as reference temperature for the data analysis. The whole inner part of the reactor was first filled with cylindrical rings made of quartz glass with an outer diameter of $12 \mathrm{~mm}$, an inner diameter of $8 \mathrm{~mm}$ and $12 \mathrm{~mm}$ long, forming a packed bed with an average porosity of $84 \mathrm{vol.-} \%$. The average porosity was estimated by conducting experiments in water using the original reactor design with three different overall filling levels, starting with an empty reactor to guarantee a random packed bed arrangement at each repetition. Molten tin $(7.25 \mathrm{~kg})$ was added subsequently from a supply tank placed above the reactor, leading to a liquid metal upper surface position (filling level) of $1050 \mathrm{~mm}$ at $1000^{\circ} \mathrm{C}$. The feed gas supply, either pure methane (purity 99.9995 vol.-\%) or a mixture diluted with nitrogen (purity 99.9999 vol.-\%) in the range of 0 vol.- $\%$ to 90 vol.- $\%$ was volume flow controlled at $\mathrm{STP}\left(\mathrm{T}_{\mathrm{n}}=0{ }^{\circ} \mathrm{C}, \mathrm{p}_{\mathrm{n}}=1.013\right.$ bar $)$. The feed gas was injected and pressure monitored at the bottom of the quartz glass reactor via a single orifice $(\varnothing 0.5 \mathrm{~mm})$. The product gas left the reactor at the top and was subsequently filtered via a sintered metal element (pore size $0.5 \mu \mathrm{m}$ ) with pressure sensors at both ends of the reactor. Afterwards, the product gas was analysed by a gas chromatograph (GC) with two separation columns (HayeSep N, molecular sieve 13X) and a Thermal Conductivity Detector using argon as carrier gas. Based on the GC measurements, mole fractions of methane, hydrogen, nitrogen, 
ethane, ethylene and acetylene in the product gas were estimated at various operating conditions. A summary of the experimental operating conditions is presented in Table 2.

Table 2: Summary of experimental operating conditions

\begin{tabular}{ll}
\hline Reference temperatures in ${ }^{\circ} \mathrm{C}$ & $930-1175$ \\
Feed gas volume flow rates in $\mathrm{ml}_{\mathrm{n}} / \mathrm{min}$ & $50-200$ \\
Inlet nitrogen volume fractions in vol.-\% & $0-90$ \\
\hline
\end{tabular}

\section{Results and Discussion}

To quantify the performance of the methane cracking process, experiments at various operating conditions were performed at steady state conditions. The hydrogen yield $\mathrm{Y}_{\mathrm{H}_{2}, \mathrm{CH}_{4}}$ is used as an indicative parameter to estimate the performance of the process:

$$
Y_{H_{2}, C H_{4}}=\frac{\dot{N}_{1} \cdot y_{H_{2}, 1}}{2 \cdot \dot{N}_{C_{H_{4}, 0}}}
$$

where $\dot{N}_{1}$ is the total outlet molar flow rate with nitrogen as dilution gas.

$$
\dot{N}_{1}=\frac{\dot{N}_{N_{2}, 0}}{y_{N_{2}, 1}}
$$

The resulting hydrogen volume flow rate at the reactor outlet, referring to STP, is derived from

$$
\dot{V}_{H_{2}, 1}=\frac{2 \cdot \dot{N}_{C_{4}, 0} \cdot Y_{H_{2}, C H_{4}} \cdot R_{g} \cdot T_{n}}{p_{n}}
$$

For experiments without the presence of nitrogen as dilution gas or intermediates, the hydrogen yield can be obtained by

$$
Y_{H_{2}, \mathrm{CH}_{4}}=\frac{y_{H_{2}, 1}\left(1+X_{C_{4}}\right)}{2}
$$

whereas $\mathrm{X}_{\mathrm{CH}_{4}}$ represents the methane conversion

$$
X_{C_{4}}=\frac{1-y_{C H_{4}, 1}}{1+y_{C_{4}, 1}}
$$

In this case, the methane conversion equals the hydrogen yield and the selectivity is one. Thermodynamic calculations are based on 


$$
\frac{4 \cdot Y_{H_{2}, \mathrm{CH}_{4}}{ }^{2}}{1-{Y_{H_{2}, C H_{4}}}^{2}}\left(\frac{p}{p_{n}}\right)^{2}=\exp \left(\frac{-\Delta G^{0}}{R_{g} \cdot T}\right)
$$

by using the temperature dependent Gibbs free energy $\Delta G^{0}$ from Ginsburg et al. [15] and equation (1). Their proposal for the Gibbs free energy indicates the chance for methane decomposition at temperatures above $547^{\circ} \mathrm{C}\left(\Delta \mathrm{G}^{0}=0\right)$, whereas thermodynamic equilibrium results are only valid for infinite residence times and without the application of catalysts, which reduce the activation energy to enhance the reaction rate.

With regards to the present study, based on a previous sensitivity analysis, the temperature and the gas residence time have strongest influence on the process [12]. It was also shown, that the heat transfer limitation is on the gas phase side due to very high Biot numbers and the core temperature of bubbles with equivalent diameters in the range of 3-10 $\mathrm{mm}$ reach their surface temperature in less than $0.5 \mathrm{~s}$. For this instance the process depends on the kinetics while the heat transfer should not be the limiting factor. Fundamental process evaluations were not proceeded as the impact of gas-phase reactions, above the liquid metal interface, on the overall hydrogen yield is unknown. In both, the liquid metal part and the upper part, non-isothermal conditions are present, whereas whether in the liquid part nor in the upper part the residence time is accurately known with the presence of a packed bed. Also the influence of the produced carbon on the residence time in the upper part and the kinetics is not clear. There are several authors proposing different reaction kinetic data. While the reaction orders for carbon catalysts were estimated in the range of $0.5-1[16,17,18]$, proposals for non-catalytic methane decomposition differ between first and second order [19, 20]. Additionally within the proposed reaction orders, the proposed kinetic parameters differ significantly. For this instance, determining the influence of the gas residence time requires further experiments with clearly distinguishable parameter variations.

Fig. 2 shows the experimental hydrogen yield as a function of the applied methane volume flow rate in the temperature range between $930{ }^{\circ} \mathrm{C}$ and $1175^{\circ} \mathrm{C}$, using pure methane as feed gas. In general, the hydrogen yield increases with the applied liquid metal temperature and with decreasing volume flow rates, whereas the dependency of the applied methane volume flow rate is moderate compared to the influence of the temperature. Another promising finding during the experiments is the absence of remarkable amounts of intermediates like ethane, ethylene or acetylene. A maximum mole fraction of 0.2 mol- $\%$ ethane and 1.5 mol- $\%$ ethylene were detected at $1000{ }^{\circ} \mathrm{C}$, whereas no acetylene was measured. This finding is in accordance with the investigations of Guéret et al. [21], who mentioned the favourable production of ethylenic species below $1200{ }^{\circ} \mathrm{C}$ without the formation of acetylene. As a consequence, the 
hydrogen yield almost equals the methane conversion and hydrogen separation from the product gas should not be complex.

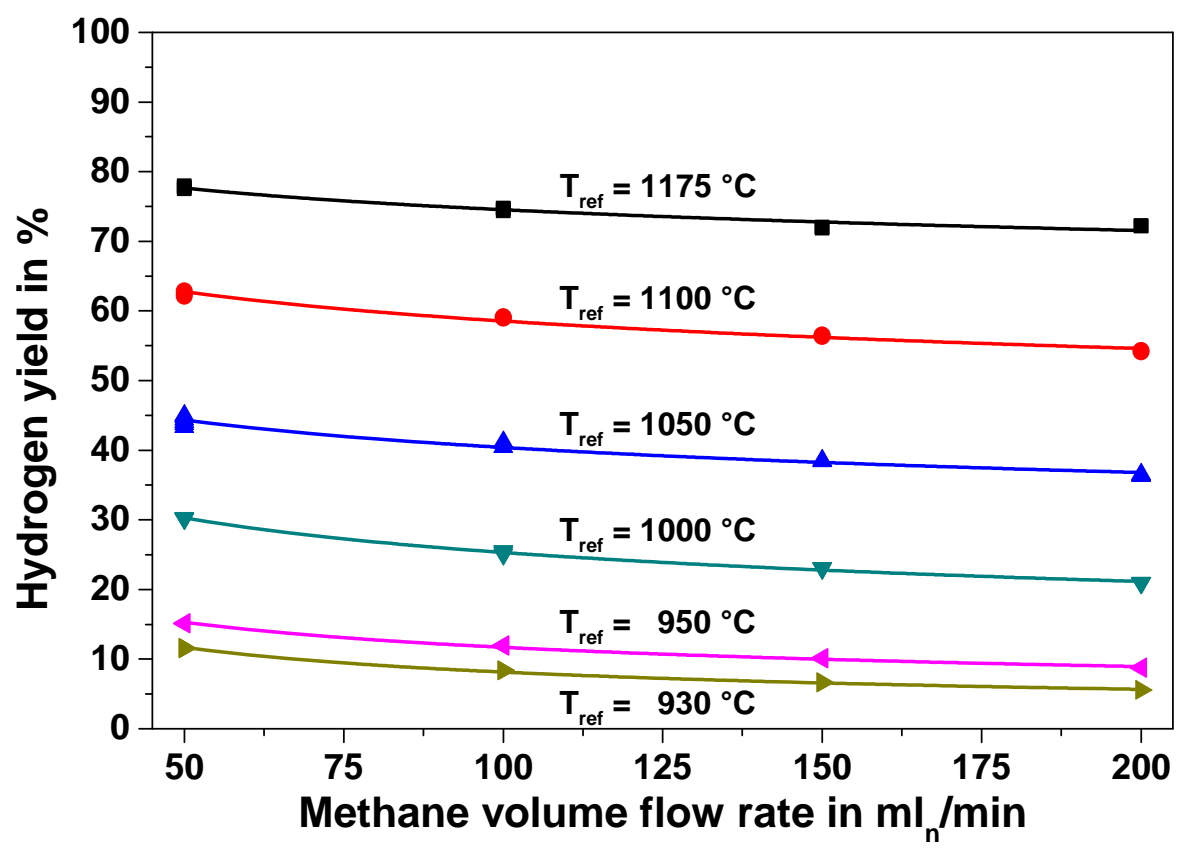

Fig. 2: Hydrogen yield as a function of methane volume flow rate at different reference temperatures with pure methane as feed gas.

\subsection{Influence of temperature, packed bed and filling level}

In order to evaluate the performance of the experimental setup in terms of the necessary liquid metal temperature and the applied packed bed design, the present results are compared with previous experimental results obtained by Geißler et al. [12] at lower temperatures between 820 ${ }^{\circ} \mathrm{C}$ and $1000{ }^{\circ} \mathrm{C}$ in a reactor filled with quartz glass (QG) fragments (average porosity of 76 vol.-\%). The reactor consisted of two sections: pure tin $(250 \mathrm{~mm})$ and a tin-QG fragment combination $(850 \mathrm{~mm})$, resulting in an overall tin filling level of $1100 \mathrm{~mm}$. In contrast to the previous experiment, the present experiment was conducted applying the packed bed (average porosity 84 vol.- $\%$ ) along the whole tin filling length of $1050 \mathrm{~mm}$. Fig. 3 compares the hydrogen yields as a function of the reference temperature in the reactor at the minimum and maximum investigated pure methane volume flow rates $50 \mathrm{ml} / \mathrm{min}$ and $200 \mathrm{ml} / \mathrm{min}$ for the two different packed bed designs, the present cylindrical rings and the quartz glass fragments. 


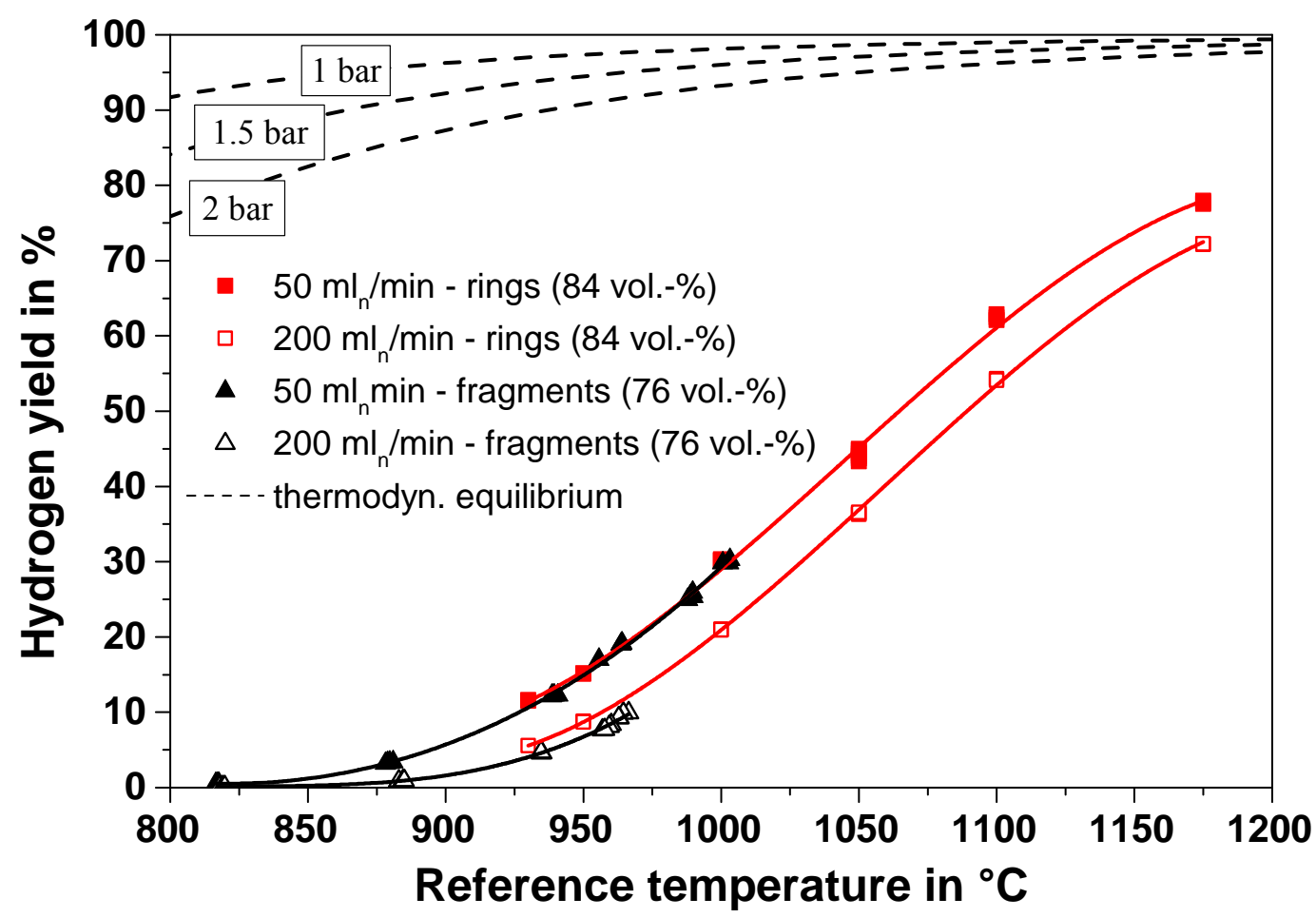

Fig. 3: Hydrogen yield as a function of temperature at $50 \mathrm{ml}_{\mathrm{n}} / \mathrm{min}$ and $200 \mathrm{ml}_{\mathrm{n}} / \mathrm{min}$ pure methane volume flow rate for two different packed bed design: cylindrical rings (porosity 84 vol.-\%) from the current study and quartz glass fragments (porosity 76 vol.-\%) published earlier in Geißler et al. [12] and equilibrium hydrogen yields as a function of temperature at 1 bar, 1.5 bar and 2 bar (dashed lines).

As seen from Fig. 3, both reactor designs indeed lead to similar hydrogen yields in the temperature range of $820-1000{ }^{\circ} \mathrm{C}$. Although the reactor designs are very similar, there are a few differences that could affect the residence times which in turn are expected to influence the hydrogen yield. Some of the differences are: the shape and size of the material used for the packed bed and the resulting porosity or the filling level. However, as seen from Fig. 3, the differences in the hydrogen yields are minor under similar operating conditions leading us to the conclusion that the residence times were also very similar in both reactor designs and the geometry at this scale factor has no impact.

Besides the experimental data, Fig. 3 shows the equilibrium hydrogen yield in the investigated temperature range at 1 bar, 1.5 bar and 2 bar. The impact of system pressure on the thermodynamic equilibrium should be considered in the process as the pressure drop along the column is around 0.7 bar, mainly resulting from the hydrostatic pressure of the liquid tin. Following the principal of Le Chatelier, the equilibrium should tend to methane by increasing the system pressure, which is represented by the theoretical calculations. By comparing the experimental results with the equilibrium hydrogen yield in the investigated temperature range, especially at low temperatures, the experimental data is far away from equilibrium hydrogen yields in relation to the deviation at $1175^{\circ} \mathrm{C}$. With respect to the temperature dependent reaction 
kinetics the hydrogen yield increases with increasing temperature. In contrast the gas residence time should decrease with increasing temperature as a consequence of growing bubbles and higher terminal velocities resulting from the volume expansion of the methane decomposition reaction besides the influence of the pressure drop. In general, especially at low liquid metal temperatures, the gas residence time should be enhanced to approach to equilibrium hydrogen yield by increasing the liquid metal column length or by applying a packed bed with better performance.

\subsection{Feed gas dilution effect}

To study the effect of methane dilution on the hydrogen yield, the measurements shown in Fig. 2 , obtained with pure methane were repeated with 50 vol.- $\%$ nitrogen, serving as an inert diluent in the feed gas. The resulting hydrogen yields were compared with the data obtained with undiluted methane and shown in Fig. 4. At temperature levels above $1000{ }^{\circ} \mathrm{C}$ the estimated hydrogen yields for 50 vol.-\% nitrogen dilution in the feed gas are higher but within a relative GC error of $2 \%$. For temperature levels below $1000{ }^{\circ} \mathrm{C}$ the hydrogen yields appear to be unaffected by the dilution through the entire range of volume flow rates applied during the experiments.

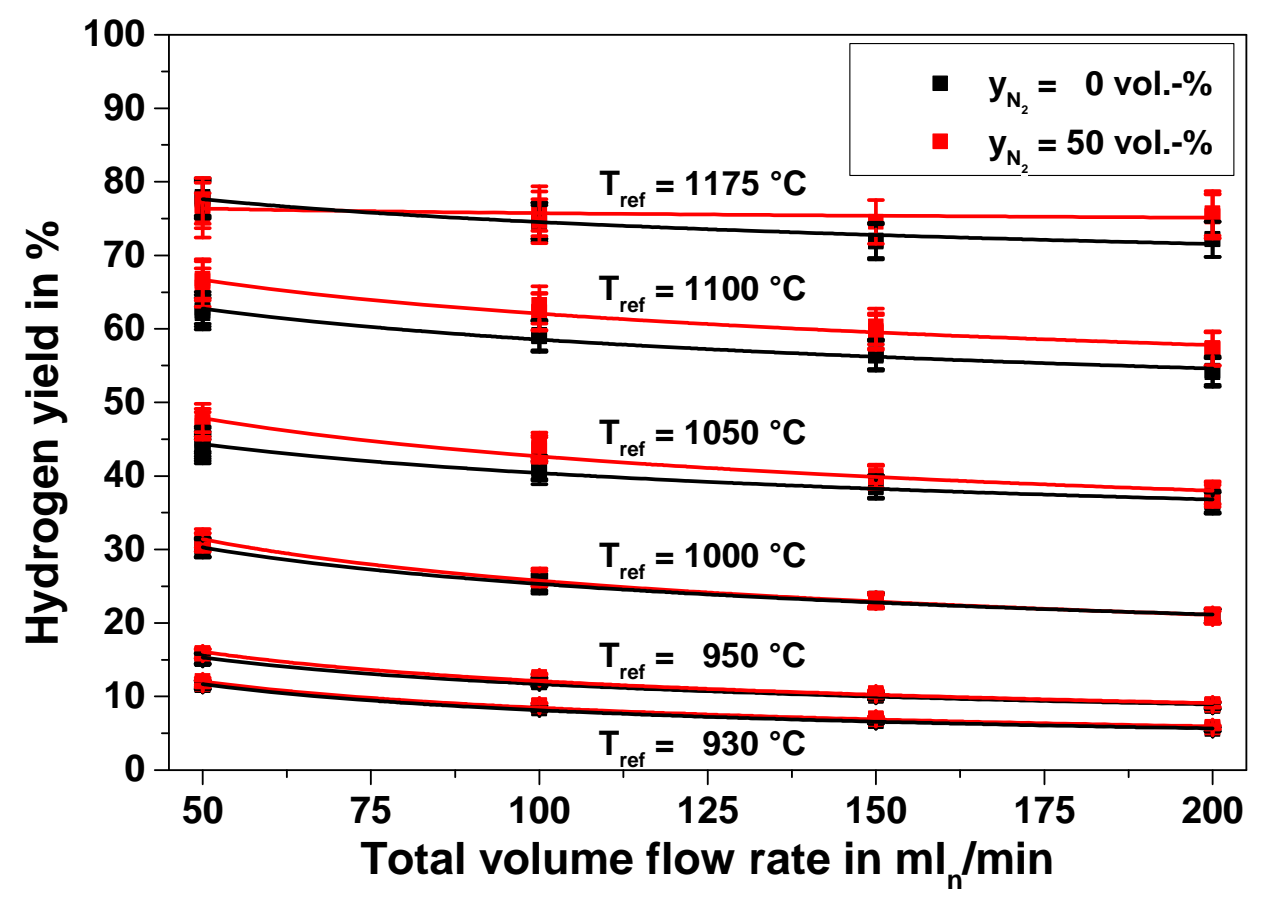

Fig. 4: Hydrogen yield as a function of the applied total volume flow rate (methane + nitrogen) at different reference temperatures and two different initial nitrogen feed gas volume fractions 0 vol.- $\%$ and 50 vol.- $\%$. Error bars resulting from $2 \%$ relative GC error. 
To further examine the influence of feed gas dilution on the hydrogen yield, the methane was diluted with varying nitrogen inlet volume fractions in the range of 0 to 90 vol.- $\%$ at a constant total volume flow rate of $100 \mathrm{mln} / \mathrm{min}$. Results obtained at various reference temperatures are shown in Fig. 5. It could be seen from the figure that the influence of the feed gas dilution on the hydrogen yield was minor. Even though the feed gas dilution has a positive influence on the hydrogen yield, the subsequent reduction in the final hydrogen production rate (depending on the dilution) is a major disadvantage and therefore not recommended. For example, at the temperature level of $1175^{\circ} \mathrm{C}$ and $100 \mathrm{ml} / \mathrm{min}$ pure methane as feed gas, which also equals an total volume flow rate of $100 \mathrm{ml} / \mathrm{min}$, the hydrogen output using equation (4) reaches a value of $150 \mathrm{mln} / \mathrm{min}$ whereby at $100 \mathrm{mln} / \mathrm{min}$ total volume flow rate the applied methane volume flow diluted with 50 vol.- $\%$ nitrogen is $50 \mathrm{mln} / \mathrm{min}$, the hydrogen output is only $75 \mathrm{mln} / \mathrm{min}$.

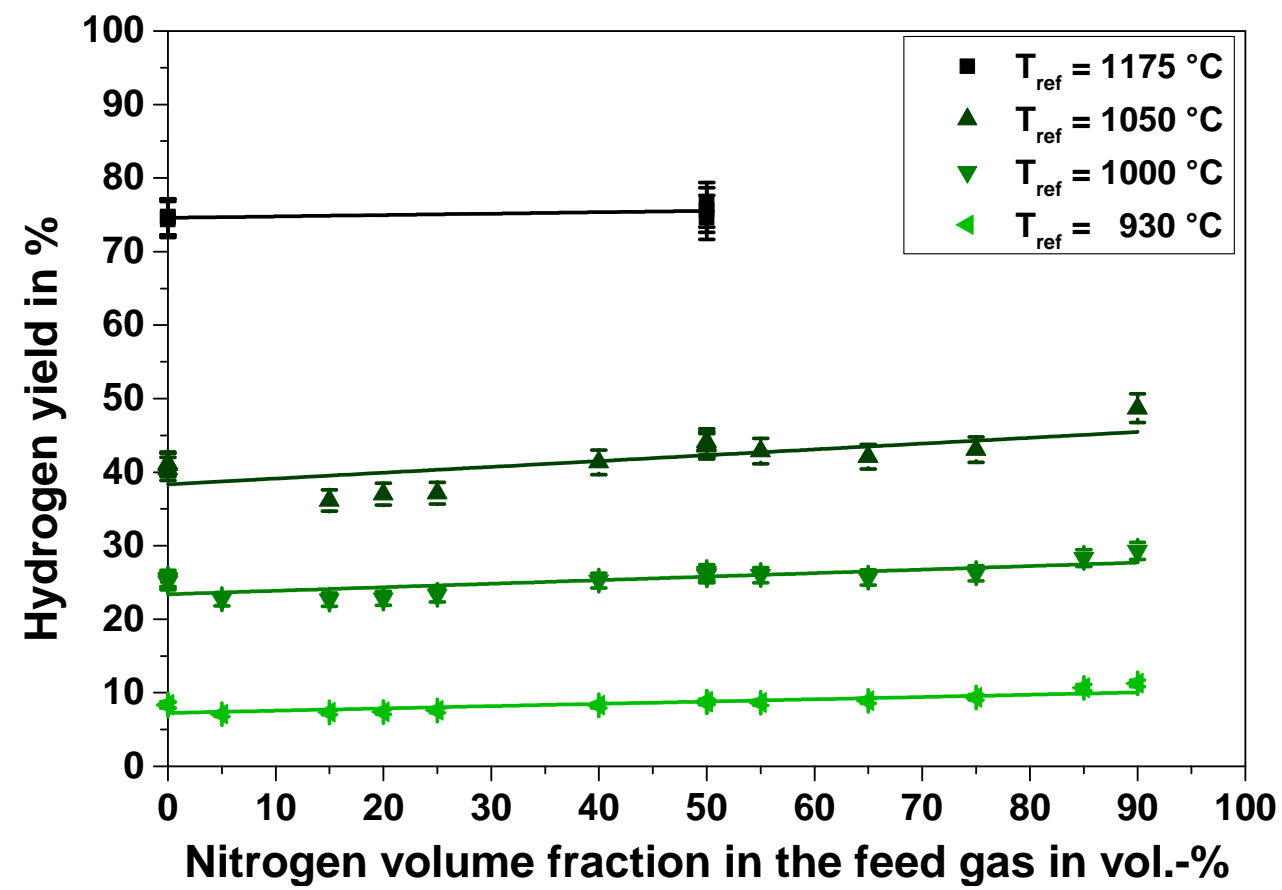

Fig. 5: Hydrogen yield as a function of the initial nitrogen volume fraction at selected reference temperatures and a constant total volume flow rate (methane + nitrogen) of $100 \mathrm{ml}_{\mathrm{n}} / \mathrm{min}$. Error bars resulting from $2 \%$ relative GC error.

Feed gas dilution/substitution with an inert gas might have an important role to play when the reaction needs to be controlled/paused for a certain amount of time while the gas flow through the orifice needs to be maintained, for example, when the carbon is being removed from the reactor. Without applying minimum the hydrostatic pressure of the column as pressure in front of the orifice, liquid metal refluxes through the gas injector can occur. Refluxing and the possible solidification of the liquid metal in the feed gas tube would lead to clogging and subsequent reactor breakdown and should therefore be prevented. 


\subsection{Carbon location and formation}

Solid carbon deposition on the hot reactor walls during the process and the subsequent reactor clogging is a major issue as it prevents the continuous operation of the reactor. The present process is expected to deliver the carbon in particulate or powder form. However, to develop concepts for carbon removal from the reactor for a potential later upscaling of the process, deeper knowledge about the formation and location of the produced carbon, as well as its characteristics, is necessary. For this reason, the solidified cross sections of the liquid metal inventory were analysed and BET (adsorption technique according to Brunauer, Emmett and Teller), XRD (X-ray diffraction), EDX (energy dispersive X-ray spectroscopy) measurements and SEM (Scanning electron microscopy) analyses were performed on the carbon samples. Fig. 6 shows cross sections of the reactor inventory at different reactor levels. Within the metal/packed bed inventory there seems to be no carbon accumulation next to the cylindrical rings; also the tin remained pure without any traces of carbon. During the cooling process, the reactor was continuously flushed with nitrogen $(100 \mathrm{mln} / \mathrm{min}$ volume flow rate). For this instance, the gas bubbling conditions should have been comparable with the conditions during the experimental runs. For this instance, we expect the original separation mechanism, a combination of separation by carbon-liquid metal density differences and gas flushing. The separation due to density differences works at any time and the gas flushing was maintained until the column was solidified. For this instance, we expect no impact of cooling the reactor on the distribution of the carbon inside of the inventory part.

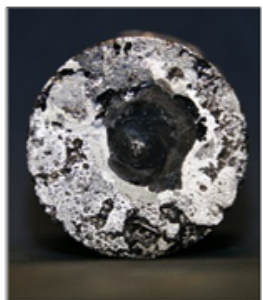

$0 \mathrm{~mm}$

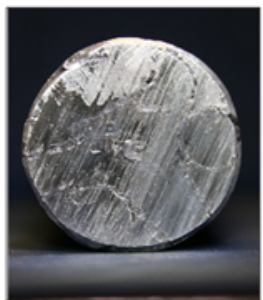

$600 \mathrm{~mm}$

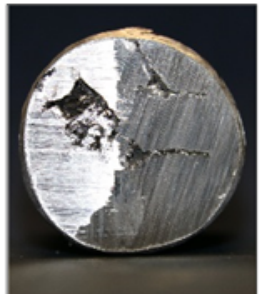

$50 \mathrm{~mm}$

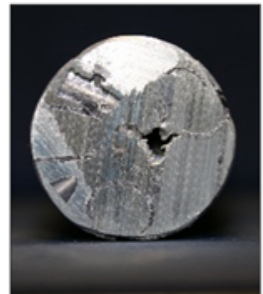

$800 \mathrm{~mm}$
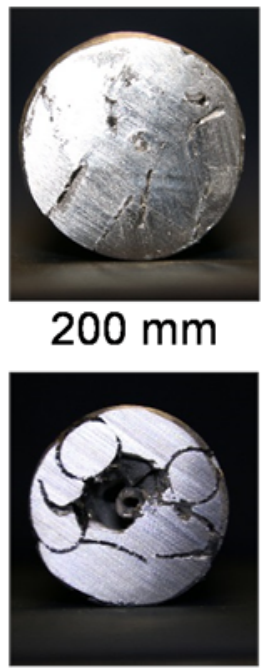

$950 \mathrm{~mm}$

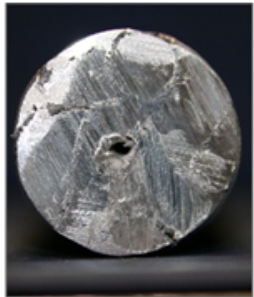

$400 \mathrm{~mm}$

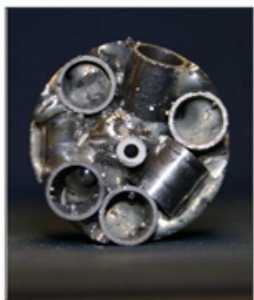

$1000 \mathrm{~mm}$

Fig. 6: Post-experimental cross sections of the solidified reactor inventory at different reactor levels starting from the bottom of the reactor at the single orifice $(0 \mathrm{~mm})$. 
While disassembling the quartz glass reactor after 15 days of operation, a thin carbon layer, around $10 \mu \mathrm{m}$ in thickness, was found between the liquid metal-packed bed inventory and the quartz glass reactor wall. SEM images at different magnification factors in Fig. 7 show the formation of the layer at $100 \mathrm{~mm}$ (left) and $700 \mathrm{~mm}$ (right) above the orifice. The produced carbon appears in a spherical shape in the relatively cold region closer to the orifice (at 100 $\mathrm{mm}$ ) whereas in the area located in the hottest part of the reactor, at $700 \mathrm{~mm}$, the carbon could have formed nanotubes. The formation of nanotubes during the experiments is comparable with the chemical vapour deposition (CVD) process that was developed for the production of single walled nanotubes using methane as feed gas and investigated by Kong et al. [22] or Brüggert et al. [23].
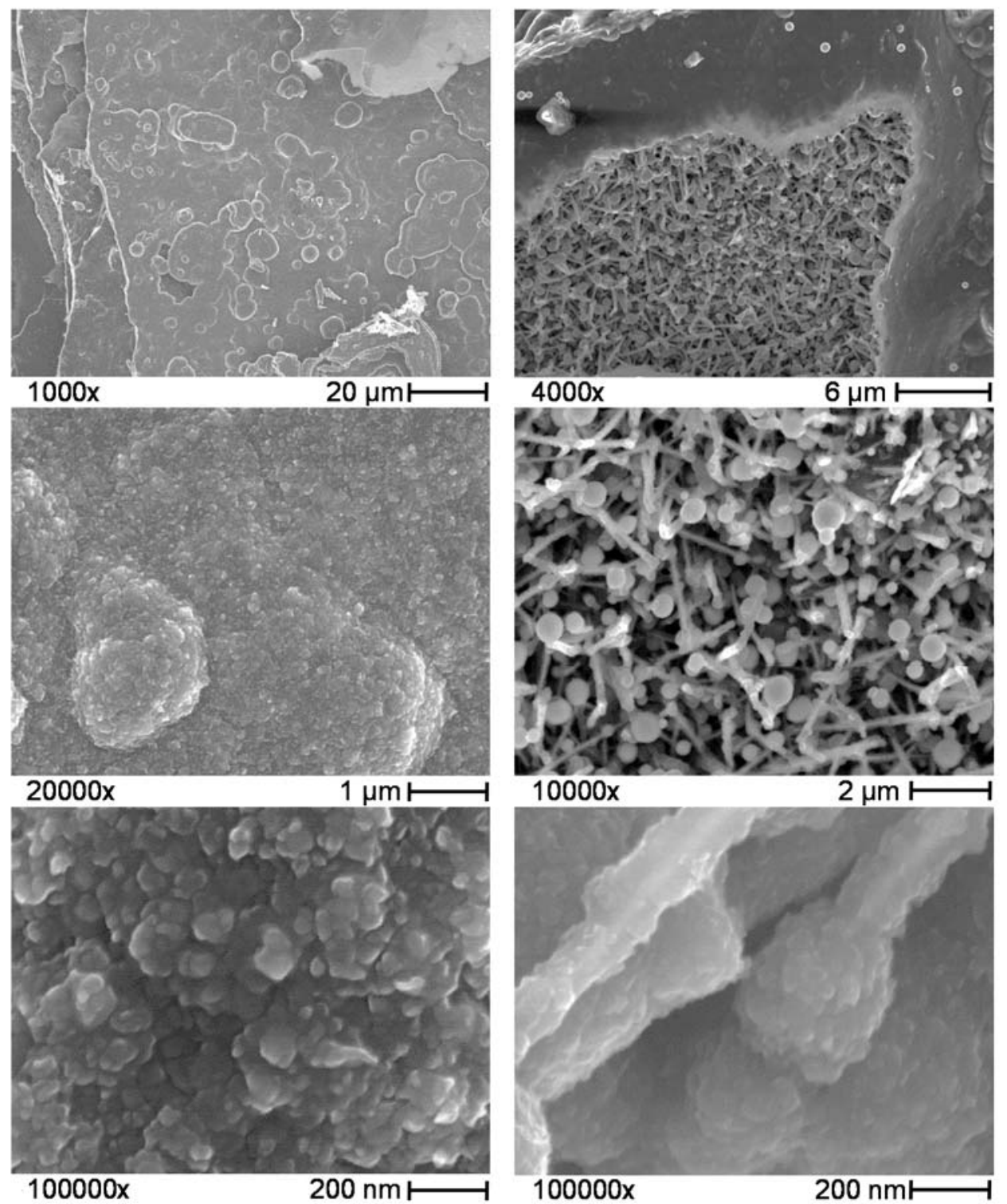

Fig. 7: SEM images of the carbon found in the thin layer between the liquid metal-packed bed inventory and the quartz glass reactor wall at different locations above the orifice $100 \mathrm{~mm}$ (left) and $700 \mathrm{~mm}$ (right). 
In the upper part of the reactor, above the liquid metal surface, a mixture of the present packed bed and the produced carbon, appearing as a powder, was found. Regarding the observed amount, most of the produced carbon accumulated in this area. A smaller amount, transported by the product gas, was collected in the filter element between the off-gas tube and the GC. The carbon separation due to density differences between carbon and tin appears to be working as expected, enabling the application of further carbon separation methods, like flushing the upper part with an inert gas stream and therefore continuous process operation without clogging. Fig. 8 shows SEM images of the produced carbon powder at different spots in the upper part above the upper liquid metal surface starting from the orifice at a) $1268 \mathrm{~mm} \mathrm{~b}) 1240 \mathrm{~mm}$ c) $1140 \mathrm{~mm}$ d) $1050 \mathrm{~mm}$. The carbon powder appears in the form of flake shaped agglomerations in the size range of $15 \mu \mathrm{m}$ to $20 \mu \mathrm{m}$ consisting of single particles with sizes between $40 \mathrm{~nm}$ and $100 \mathrm{~nm}$, assuming spherical shape. During the experiments, the mentioned gas filter element in the off gas tube were regularly checked and replaced. SEM images of the carbon samples taken from the filter elements exhibited similar shapes as the carbon found above the liquid metal interface. The specific surface area of the carbon, based on BET measurements, varied from $17 \mathrm{~m}^{2} / \mathrm{g}$ to $40 \mathrm{~m}^{2} / \mathrm{g}$. Measurements were conducted with carbon, which remained in the reactor for the whole experimental campaign as well as with carbon samples, which were found in the filter element right after a sampling run at constant temperature and volume flow rate. The surface areas of both samples fall within a relatively narrow range when compared to the time periods of their stays in the system, therefore the deactivation of potential catalytic carbon is unlikely. Further reaction of non-reacted methane in the off gas filter and therefore deactivation of the potential carbon catalyst is not possible, as the off gas filter operated at room temperature. According to investigations on carbon catalysts from Muradov [24] for the decomposition of methane, the produced carbon has most likely no or only minor catalytic effect on the process as its specific surface area is too small to increase the methane decomposition rate significantly. Another study from Lee et al. [18] showed a slight catalytic effect of the produced carbon, whereas an investigations of active sites on carbon catalysts revealed only limited capability to correlate the catalytic activity with the surface area.

Additional EDX measurements on carbon samples (SEM images shown in Fig. 8) found in the uppermost part of the reactor below the upper flange, revealed that the carbon was very pure $(99.30 \mathrm{wt}-\%)$ and contained only minor traces of tin $(0.70 \mathrm{wt}-\%)$. The contamination of the carbon with tin in the upper part could have occurred from tin splashes off the surface but more likely during the filling process in which the liquid tin flows from the supply tank located above 
the reactor through the whole packed bed inventory. The analysed carbon seems to be not well crystallized, indicated by the week XRD reflection pattern.
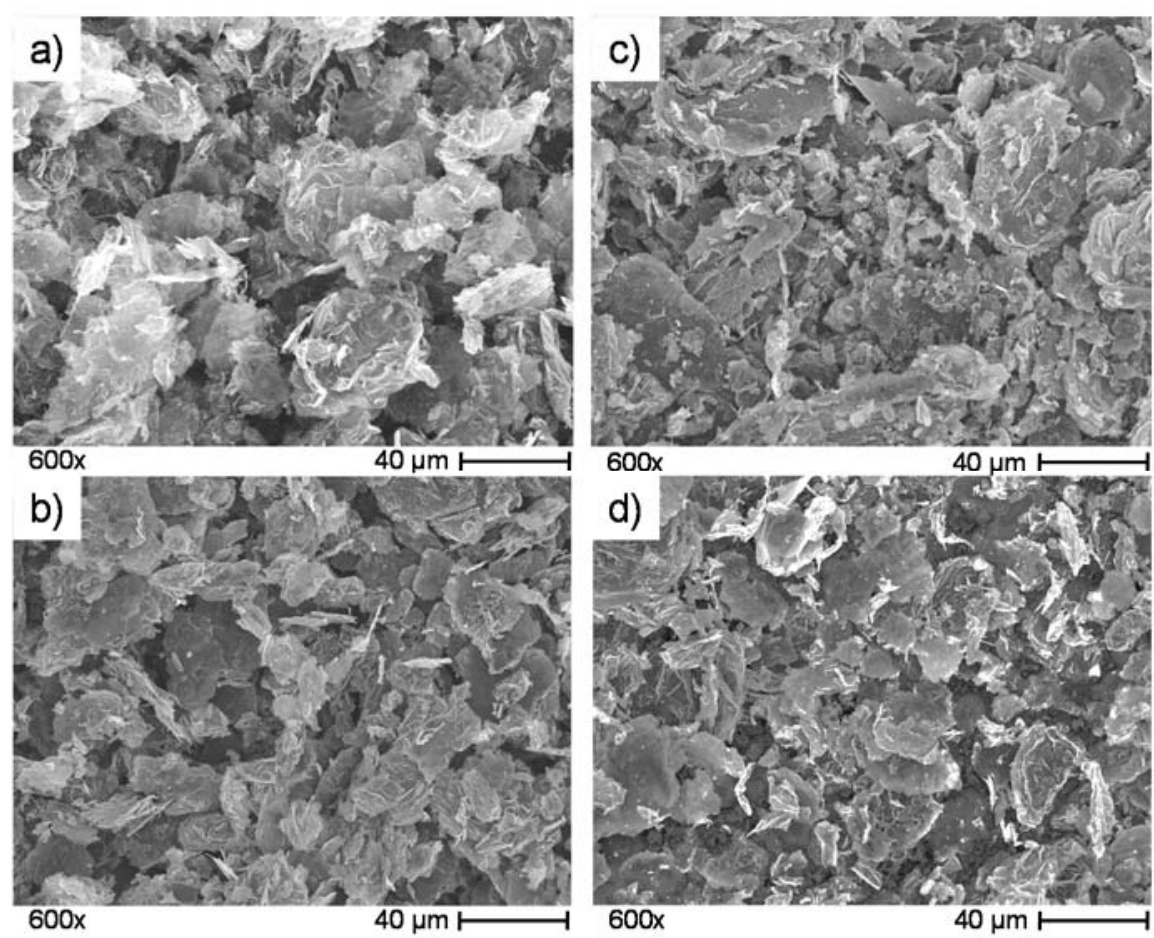

Fig. 8: SEM images of the carbon retrieved from the $200 \mathrm{~mm}$ space between the liquid metal surface $(1050 \mathrm{~mm})$ and the upper flange located at the end of the quartz glass reactor (1268 mm): a) $1268 \mathrm{~mm} \mathrm{~b}) 1240 \mathrm{~mm} \mathrm{c}) 1140$ $\mathrm{mm} \mathrm{d)} 1050 \mathrm{~mm}$

\section{Conclusions}

The technical feasibility of methane decomposition in a liquid metal bubble column reactor fitted with a liquid tin packed bed inventory at temperatures up to $1175{ }^{\circ} \mathrm{C}$ was successfully demonstrated. Experiments were conducted at six different temperature levels in the range of $930{ }^{\circ} \mathrm{C}$ to $1175^{\circ} \mathrm{C}$ and feed gas volume flow rates between $50 \mathrm{mln} / \mathrm{min}$ and $200 \mathrm{mln} / \mathrm{min}$. The maximum hydrogen yield of $78 \%$ was obtained at $1175{ }^{\circ} \mathrm{C}$ and $50 \mathrm{ml} / \mathrm{min}$ pure methane volume flow rate. Besides hydrogen, a maximum of 1.5 mol- $\%$ of intermediates were detected in the product gas. Diluting the methane feed gas with nitrogen in the range of 0 vol.- $\%$ to 90 vol.- $\%$, revealed no significant influence on the resulting hydrogen yield in the investigated temperature range. The present experimental results in the presence of quartz glass cylindrical rings with a porosity of 84 vol.- $\%$ were compared with previous results using quartz glass fragments with a porosity of 76 vol.- $\%$ from Geißler et al. [12]. Between both experiments, no major differences in terms of hydrogen yield were found. During the present experiments, no clogging issues due to solid carbon deposition on reactor walls or other parts occurred. The produced carbon mainly accumulated above the liquid metal interface in powder form with 
particle sizes in the range of $15 \mu \mathrm{m}$ to $20 \mu \mathrm{m}$. Additionally, a thin carbon layer, most likely containing carbon nanotubes, was deposited between the quartz glass reactor wall and the inventory.

Acknowledgment

This study was financially supported within the framework of a collaboration contract by the Institute for Advanced Sustainability Studies (IASS) and by the Helmholtz Society within the Helmholtz Alliance for Liquid Metal Technologies (LIMTECH). The authors wish to thank the following people for their invaluable support and comments: Andreas Jekel, Dr. Jürgen Konys, Dr. Carsten Schroer and Thomas Emmerich.

\section{Nomenclature}

$\begin{array}{lll}\mathrm{d} & \text { Equivalent bubble diameter } & {[\mathrm{mm}]} \\ \Delta G^{0} & \text { Standard Gibbs free energy } & {[\mathrm{J} / \mathrm{mol}]} \\ \Delta \mathrm{H}_{\mathrm{R}}^{0} & \text { Standard reaction enthalpy } & {[\mathrm{J} / \mathrm{mol}]} \\ \dot{\mathrm{N}} & \text { Molar flow rate } & {[\mathrm{mol}]} \\ \mathrm{p} & \text { Absolute pressure } & {[\mathrm{Pa}]} \\ \mathrm{R}_{\mathrm{g}} & \text { Universal gas constant } & {[\mathrm{J} / \mathrm{mol} / \mathrm{K}]} \\ \mathrm{T} & \text { Temperature } & {[\mathrm{K}]} \\ \mathrm{X} & \text { Conversion } & {[-]} \\ \mathrm{y} & \text { Mole fraction in the gas phase } & {[-]} \\ \mathrm{Y} & \text { Yield } & {[-]}\end{array}$

\section{Greek letters}

$\tau$

Mean residence time

\section{Subscripts}

$\begin{array}{ll}\mathrm{B} & \text { Bubble } \\ \mathrm{CH}_{4} & \text { Methane } \\ \mathrm{G} & \text { Gas } \\ \mathrm{H}_{2} & \text { Hydrogen } \\ \mathrm{LM} & \text { Liquid metal } \\ \mathrm{N}_{2} & \text { Nitrogen } \\ \mathrm{n} & \text { Standard conditions } \\ \mathrm{S} & \text { Solid } \\ \mathrm{UP} & \text { Upper part } \\ 0 & \text { Inlet condition } \\ 1 & \text { Outlet condition }\end{array}$

Abbreviations

$\begin{array}{ll}\text { GC } & \text { Gas chromatograph } \\ \text { QG } & \text { Quartz glass }\end{array}$




\section{References}

[1] C.-J. Chen, M.H. Back, and R.A. Back. The thermal decomposition of methane. I. Kinetics of the primary decomposition to $\mathrm{C} 2 \mathrm{H} 6+\mathrm{H} 2$; Rate constant for the homogeneous unimolecular dissociation of methane and its pressure and dependence. Canadian Journal of Chemistry, 53:3580-3590, 1975.

[2] A. Abánades, E. Ruiz, E.M. Ferruelo, F. Hernández, A. Cabanillas, J.M. Martínez-Val, J.A. Rubio, C. López, R. Gavela, G. Barrera, C. Rubbia, D. Salmieri, E. Rodilla, and D. Gutiérrez. Experimental analysis of direct thermal methane cracking. International Journal of Hydrogen Energy, 36(20):12877-12886, 2011.

[3] A. Abánades, R. K. Rathnam, T. Geißler, A. Heinzel, K. Mehravaran, G. Müller, M. Plevan, C. Rubbia, D. Salmieri, L. Stoppel, S. Stückrad, A. Weisenburger, H. Wenninger, and T. Wetzel. Development of methane decarbonisation based on liquid metal technology for CO2-free production of hydrogen. International Journal of Hydrogen Energy, pages -, 2015.

D. Tyrer. Production of hydrogen, April 28 1931. US Patent 1,803,221.

[5] M. Steinberg. Fossil fuel decarbonization technology for mitigating global warming. International Journal of Hydrogen Energy, 24(8):771-777, 1999.

[6] P.N. Martynov, A.V. Gulevich, Yu.I. Orlov, and V.A. Gulevsky. Water and hydrogen in heavy liquid metal coolant technology. Progress in Nuclear Energy, 47:604 - 615, 2005.

[7] A.V. Gulevich, P.N. Martynov, V.A. Gulevsky, and V.V. Ulyanov. Technologies for hydrogen production based on direct contact of gaseous hydrocarbons and evaporated water with molten Pb or Pb-Bi. Energy Conversion and Management, 49(7):1946 - 1950, 2008.

[8] D. Paxman, S. Trottier, M. Nikoo, M. Secanell, and G. Ordorica-Garcia. Initial experimental and theoretical investigation of solar molten media methane cracking for hydrogen production. Energy Procedia, 49:2027-2036, 2014.

[9] I. Schultz and D. W. Agar. Decarbonisation of fossil energy via methane pyrolysis using two reactor concepts: Fluid wall flow reactor and molten metal capillary reactor. International Journal of Hydrogen Energy, 40(35):11422 - 11427, 2015.

[10] M. Serban, M. A. Lewis, Ch. L. Marshall, and R. D. Doctor. Hydrogen production by direct contact pyrolysis of natural gas. Energy \& Fuels, 17(3):705-713, 2003.

[11] M. Plevan, T. Geißler, A. Abánades, K. Mehravaran, R.K. Rathnam, C. Rubbia, D. Salmieri, L. Stoppel, S. Stückrad, and Th. Wetzel. Thermal cracking of methane in a liquid metal bubble column reactor: Experiments and kinetic analysis. International Journal of Hydrogen Energy, 40(0):8020-8033, 2015.

[12] T. Geißler, M. Plevan, A. Abánades, A. Heinzel, K. Mehravaran, R.K. Rathnam, C. Rubbia, D. Salmieri, L. Stoppel, S. Stückrad, A. Weisenburger, H. Wenninger, and Th. Wetzel. Experimental investigation and thermo-chemical modeling of methane pyrolysis in a liquid metal bubble column reactor with a packed bed. International Journal of Hydrogen Energy, 40(41):14134 - 14146, 2015. 
[13] R.J. Andreini, J.S. Foster, and R.W. Callen. Characterization of gas bubbles injected into molten metals under laminar flow conditions. Metallurgical Transactions B, 8(4):625-631, 1977.

[14] F. Geiger, C.A. Busse, and R.I. Loehrke. The vapor pressure of indium, silver, gallium, copper, tin, and gold between 0.1 and 3.0 bar. International Journal of Thermophysics, 8(4):425 $-436,1987$.

[15] J. M. Ginsburg, J. Pina, T. El Solh, and H. I. de Lasa. Coke formation over a nickel catalyst under methane dry reforming conditions: Thermodynamic and kinetic models. Ind. Eng. Chem. Res., 44(14):4846-4854, 2005.

[16] N. Muradov, F. Smith, and A. T-Raissi. Catalytic activity of carbons for methane decomposition reaction. Catalysis Today, 102-103:225 - 233, 2005. 1st International Symposium on Carbon for Catalysis 1st International Symposium on Carbon for Catalysis.

[17] K. K. Lee, G. Y. Han, Ki J. Yoon, and B. K. Lee. Thermocatalytic hydrogen production from the methane in a fluidized bed with activated carbon catalyst. Catalysis Today, 9395(0):81 - 86, 2004. Selections from the presentations of the 3rd Asia-Pacific Congress on Catalysis.

[18] E. K. Lee, S. Y. Lee, G. Y. Han, B. K. Lee, T.-J. Lee, J. Hyuk Jun, and K. June Yoon. Catalytic decomposition of methane over carbon blacks for $\mathrm{CO} 2$-free hydrogen production. Carbon, 42(12-13):2641 - 2648, 2004.

[19] A. Holmen, O. A. Rokstad, and A. Solbakken. High-temperature pyrolysis of hydrocarbons. 1. Methane to Acetylene. Industrial \& Engineering Chemistry Process Design and Development, 15(3):439-444, 1976.

[20] M. S. Khan and B. L. Crynes. Survey of recent methane pyrolysis literature. Industrial \& Engineering Chemistry, 62(10):54-59, 1970.

[21] Chr. Guéret, M. Daroux, and Fr. Billaud. Methane pyrolysis: Thermodynamics. Chemical Engineering Science, 52(5):815 - 827, 1997.

[22] J. Kong, A. M. Cassell, and H. Dai. Chemical vapor deposition of methane for singlewalled carbon nanotubes. Chemical Physics Letters, 292:567 - 574, 1998.

[23] M. Brüggert, Z. Hu, and K.J. Hüttinger. Chemistry and kinetics of chemical vapor deposition of pyrocarbon: VI. Influence of temperature using methane as a carbon source. Carbon, 37(12):2021 - 2030, 1999.

[24] N. Muradov. Catalysis of methane decomposition over elemental carbon. Catalysis Communications, 2:89-94, 2001. 